University of Wollongong

Research Online

Faculty of Engineering - Papers (Archive)

Faculty of Engineering and Information

Sciences

October 2003

\title{
Two-Phase (Air and Water) Flow through Rock Joints: Analytical and Experimental Study
}

Buddhima Indraratna

University of Wollongong, indra@uow.edu.au

P. G. Ranjith

Nanyang Technological University, Singapore

J. R. Price

University of Wollongong

W. Gale

Strata Control Technology, Wollongong

Follow this and additional works at: https://ro.uow.edu.au/engpapers

Part of the Engineering Commons

https://ro.uow.edu.au/engpapers/177

\section{Recommended Citation}

Indraratna, Buddhima; Ranjith, P. G.; Price, J. R.; and Gale, W.: Two-Phase (Air and Water) Flow through Rock Joints: Analytical and Experimental Study 2003.

https://ro.uow.edu.au/engpapers/177

Research Online is the open access institutional repository for the University of Wollongong. For further information contact the UOW Library: research-pubs@uow.edu.au 


\title{
Two-Phase (Air and Water) Flow through Rock Joints: Analytical and Experimental Study
}

\author{
B. Indraratna, M.ASCE ; P. G. Ranjith ${ }^{2}$; J. R. Price ${ }^{3}$; and W. Gale ${ }^{4}$
}

\begin{abstract}
This research study deals with the characterization of two-phase flow in a fractured rock mass. A comprehensive mathematical model with which to predict the quantity of each flow component in a single joint is developed. A joint with two parallel walls filled with layers of water and air (stratified) is analyzed. The effects of mechanical deformation of the joint, the compressibility of fluids, the solubility of air in water, and the phase change between fluids have been taken into account to develop analytical expressions which describe the behavior at the air-water interface. The model was calibrated using a newly designed two-phase (high-pressure) triaxial cell. Tests were conducted on fractured hard rock samples for different confining pressures with inlet water and inlet air pressures. As in single-phase flow, it was found both experimentally and theoretically, that the flow quantities of each phase decreases considerably with an increase in confining stress. The results also confirm that the effect of joint deformation and compressibility of fluids governs the flow volume of two-phase flow. Good agreement was obtained between the experimental data and numerical predictions.
\end{abstract}

DOI: 10.1061/(ASCE)1090-0241(2003)129:10(918)

CE Database subject headings: Hydromechanics; Two phase flow; Joint rocks; Surface roughness.

\section{Introduction}

Two-phase flow through jointed rock media has gained increasing interest due to the important applications in water-air or oil-gas transportation through joint networks. In the underground mining environment, the potential risk of gas outbursts increases when fractures contain two-phase flow due to the decreasing desorption rate attributed to water. The practical importance of two-phase flow in geotechnical, mining, and petroleum engineering was discussed by Pruess and Tsang (1990). In two-phase-stratified flow, from this theoretical point of view, the main difficulty lies in identifying the interface between air and water phases (Nichol and Glass 2001), since the location of the interface is time dependent under external conditions such as variation of the aperture and fluid pressure. At present, satisfactory procedures are not available in the literature to estimate flow quantities occurring in multiphase flow in jointed rock. Limited attempts to analyze a combination of hydro and mechanical behavior are found in the literature with respect to gas-water fracture flow (Pruess and Tsang 1990; Rasmussen 1991; Fourar et al. 1993; and Fourar and Bories 1995). The study described herein is an extension of an earlier research paper (Indraratna and Ranjith 2001) aimed at in-

\footnotetext{
${ }^{1}$ Professor, Faculty of Engineering, Univ. of Wollongong, New South Wales 2522, Australia.

${ }^{2}$ Lecturer, School of Structural and Civil Engineering, Nanyang Technological Univ., Singapore, Singapore.

${ }^{3}$ Doctoral candidate, Faculty of Engineering, Univ. of Wollongong, New South Wales 2522, Australia.

${ }^{4}$ Principal Engineer, Strata Control Technology, Wollongong, New South Wales 2520, Australia.

Note. Discussion open until March 1, 2004. Separate discussions must be submitted for individual papers. To extend the closing date by one month, a written request must be filed with the ASCE Managing Editor. The manuscript for this paper was submitted for review and possible publication on August 27, 2001; approved on November 12, 2002. This paper is part of the Journal of Geotechnical and Geoenvironmental Engineering, Vol. 129, No. 10, October 1, 2003. OASCE, ISSN 10900241/2003/10-918-928/\$18.00.
}

troducing a new direction for analysis of multiphase flow, with special reference to jointed rock engineering.

Rasmussen (1991) investigated fracture flow under conditions of partial fluid saturation. The fracture made of two glass panels was filled with water in one portion, and the remaining portion was filled with air. He determined the air-water interface in the fracture for different capillary pressures both analytically and experimentally. Fourar et al. (1993) observed different flow patterns via two parallel glass plates and two parallel brick layers, which were not subjected to external loads. The valuable experimental results ascertained by him can be directly applied for simplified two-phase flow analysis, but are not suitable for the characterization of combined hydro-air-mechanical flow that usually takes place within rock joints under stress. Pruess and Tsang (1990) conducted a numerical analysis based on the relative permeability of two-phase flow subject to pressure difference between air and water in real rock fractures. He observed that the nature and range of the spatial correlation between apertures influence the relative permeability. It is assumed that single-phase flow phenomena can be applied when discontinuities become fully saturated with a fluid (generally water or gas). However in practice, even under fully saturated conditions, some gas may still be dissolved in water and can come out of the solution depending on the pressure changes, subsequently leading to complex flow patterns.

To the knowledge of the writers, the interrelation of multiphase flows, relative permeability, and the pressure variation through rock fractures has not been properly identified. Therefore, in the present study we intend to shed light on the relatively complicated two-phase flow system, and to provide a fundamental mathematical model with which to compute the quantities of each fluid phase that travel in a given joint domain. This problem is approached by considering a simplified stratified two-phase flow model that would occur in a joint element. The mechanical apertures recorded in the tests are sufficiently large that capillary pressure can be effectively ignored in the calculations, i.e., less than $5 \%$ drop in fluid pressure. The validity of this assumption is subsequently explored in greater detail. The study mainly consists of 
1. Separated flows

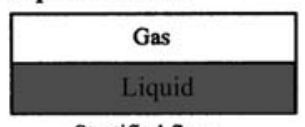

Stratified flow

2. Mixed flows

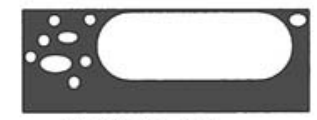

Slug flow - gas pocket in liquid film

3. Dispersed flows

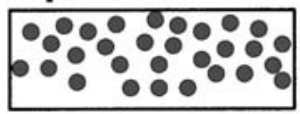

Droplet flow - gas

with liquid droplets

Fig. 1. Different flow modes of two-phase liquid and gas interaction (after Ishii 1975; Fourar and Bories et al. 1995)

two stages: development of a mathematical model and laboratory testing to verify the mathematical model using a two-phase, highpressure triaxial cell.

\section{Flow through a Single Joint}

The applicability of cubic law for flow rate calculations in rock mass has been investigated with respect to deformable rough discontinuities subjected to low levels of stress (Iwai 1976; Witherspoon et al. 1980; Tsang and Witherspoon 1981, 1983; Brown 1987). Water flow through smooth ideal joints may be treated in a similar way to flow in a pipe network. Nevertheless, in reality, the change in joint aperture under variations in stress necessitates the coupling of mechanical deformations with fluid flow characteristics. The two-phase air-water flow may be described by the characteristic components of each phase present in the mixture, their volume and mass ratio, and the homogeneity of the mixture. Classifications proposed by Ishii (1975) and by Fourar and Bories (1995) according to the topology of the flow pattern are illustrated in Fig. 1.

\section{Role of Capillary Pressure in Rock Fracture Hydraulics}

Capillary pressure $\left(p_{c}\right)$ is commonly defined as the difference between phase pressures, i.e.,

$$
p_{c}=p_{a}-p_{w}
$$

where $p_{a}=$ air pressure and $p_{w}=$ water pressure $(\mathrm{kPa})$. Capillary pressure can also be defined with respect to the surface tension between fluids $\left(T_{s}\right)$, the radii of curvature of the interface (measured orthogonally, $R_{1}$ and $R_{2}$ ), and the angle of contact $(\alpha)$ between the fracture wall and the interface:

$$
p_{c}=T_{s} \cos \alpha\left(\frac{1}{R_{1}}+\frac{1}{R_{2}}\right)
$$

When considering flow in a fracture of aperture $(e)$ in the limiting case, where $R_{2}$ is large relative to $R_{1}, R_{1}$ approaches $e / 2$ and $\alpha$ is $0^{\circ}$, Eq. (2) simplifies to

$$
p_{c}=\frac{2 T_{s}}{e}
$$

where at $20^{\circ} \mathrm{C} T_{s}$ is $72.75 \mathrm{mN} / \mathrm{m}$. From Eq. (3), the magnitude of capillary pressure is considerable for tight fractures (e.g., $140 \mathrm{kPa}$ for a $1 \mu \mathrm{m}$ aperture) but is insignificant $(<3 \mathrm{kPa})$ for fractures with an aperture of more than $50 \mu \mathrm{m}$. For fracture apertures of more than $9 \mu \mathrm{m}$, the capillary pressure is less than about $5 \%$ of the drop in phase pressure used in these experiments. For practical purposes, the fluid pressure gradients and the fracture apertures measured in these experiments render the capillary effect negligible (i.e., $p_{c}<0.05 p_{a}$ ); thus, while recognizing the implications of the model, it is assumed that the air and water pressure gradients are equal in the simplified stratified model employed in this analysis. However, if the fracture apertures were smaller and the drop in pressure across the fracture less, then capilliarity would become significant. Similar logic was argued by Keller et al. (2000) when discussing the two-phase flow behavior observed by Fourar et al. (1993) in relation to the nonaqueous phase liquid (NAPL) flow in fractured porous media.

The model was developed with the environment of active long wall faces in mind. In this regime, naturally occurring fractures in arenaceous sandstones with mean apertures of about 10 to several $100 \mu \mathrm{m}$ have been recorded by the writers. For fracture apertures of this magnitude, the potential for the development of separate rather than equivalent two-phase immiscible flow is believed to be credible given the capillary pressure-aperture relationship described above.

\section{Governing Equations for Two-Phase Flow}

In multiphase flow analysis, it is very difficult to develop a general equation that incorporates any type of flow, given the extreme variability associated with both joint geometry and roughness. Unlike flow in transparent pipes (with well-defined geometry and uniform roughness), it is not possible to directly observe flow patterns in internal rock joints in situ, although indirect methods have been applied, e.g., computer-aided tomography (CAT) scanning (Keller 1998) and transparent replicas of joints or joint analogs have been made for the purpose of observation (e.g., by Hakami and Barton 1990; Persoff and Pruess 1993; Nichol and Glass 1994). Therefore, in the writers' model, the flow pattern within the joint was assumed to be stratified flow in keeping with the foregoing discussions of the role of capillary pressure, in order to develop a simplified mathematical model. They recognized the limitations of such stratified flow, however, they considered this only fundamental for initially describing poorly understood flow phenomenon in two-phase flow through rock joints, while appreciating the future necessity to extend this model for more complex flow analysis. The flow pattern within the joint may not be purely stratified, but given the relatively smooth joints tested in this study, the assumption of stratified flow is not unreasonable. For example, the flow regime in pipes is controlled because of the large constant diameter and consistent surface roughness, but in the case of fractured rock specimens, where the joint aperture can be as small as $10^{-5} \mathrm{~m}$ and highly variable in roughness along the length, a perfect match with theory may never be found.

The joint shown in Fig. 2, which contains both gas and water layers, is initially subjected to confining and vertical stress. Fluid flow is assumed to occur only through the fracture, because the permeability of the intact rock material is assumed to be negligible, such as in the case of granite or basalt. Due to an increment 


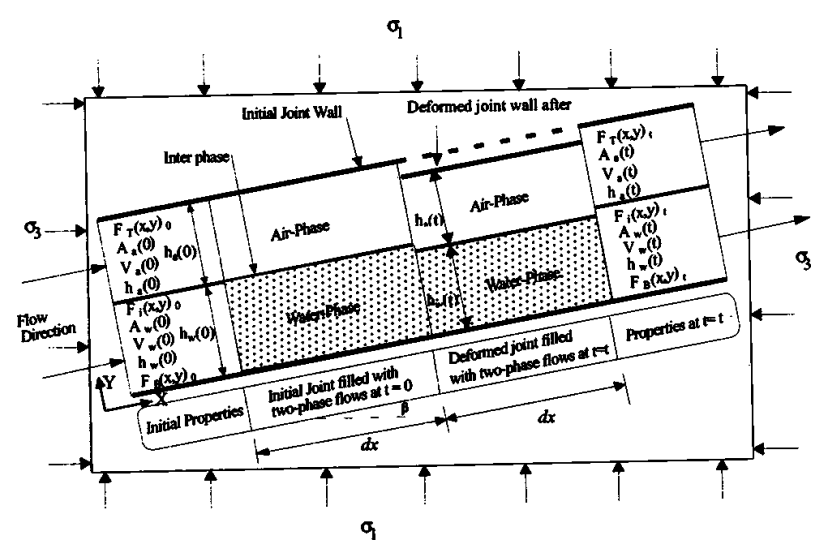

Fig. 2. Typical inclined joint filled with two-phase flows indicating change of interface and deformation of joint wall associated with change in level of stress. [Note: at the limit of negligible phase height, $S_{j w}=S_{j a}=S_{w a}$ (see Appendix A)].

of stress, the top surface of the joint is deformed a certain amount, and consequently the interface level is altered. Mechanical deformation of a joint wall due to a change of external stress $\left(\sigma_{1}\right.$ and $\sigma_{3}$ ) and the fluid pressure itself are combined in the analytical model, where factors such as the compressibility of fluids, solubility of air in water, and the change in phase of fluids are shown to influence the behavior of the air-water interface. The general procedure for analysis of two-phase flow is summarized by the flow chart given in Fig. 3, which indicates how the simplified model developed here can be used to analyze a particular aspect of two-phase flow behavior. Alternative more complex flow pattern models are currently under development as part of active research on this topic by the writers.

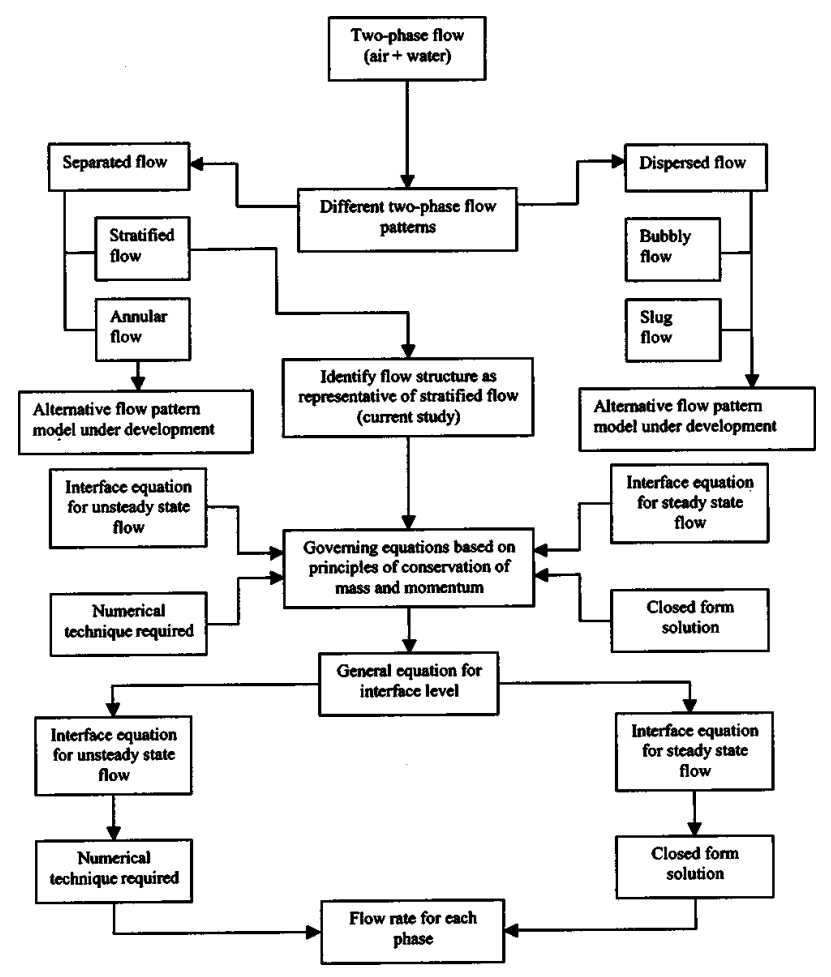

Fig. 3. Simplified analysis of two-phase stratified flow
In this model, the writers have assumed that two-phase flow through a single rock joint can be approximated using the momentum conservation equation initially developed for pipes (Wallis 1969) and adapted to include the effect of the joint inclination. The derivation of this equation is included in the Appendix.

\section{Effects of Deformation, Solubility of Air, and Compressibility of Fluids}

Here we focus on developing a mathematical expression for the flow rate of each phase based on a governing equation in the Appendix. Deformation of a joint associated with the compressibility of air and water, solubility of air in water, fluid pressure itself, or external force such as gravitational stress is discussed below. Also, changes in property of both phases and their effects on the flow rates are discussed.

\section{Effects of Solubility of Air in Water to Flow Rate}

The solubility of air in water at the equilibrium state is best described by the ideal gas law and Henry's law at certain pressure and temperature conditions (Fredlund and Rahardjo 1993):

$$
V_{d a}(t)=\left(\frac{M_{d}}{p_{a}}\right)_{t}\left(\frac{R_{g} T}{W_{a}}\right)_{t}
$$

where $V_{d a}(t)=$ volume of air dissolved in water at time $t ; M_{d}$ and $p_{a}=$ mass of air dissolved in water and absolute pressure of air, respectively; $W_{a}=$ molecular mass of air $(\mathrm{kg} / \mathrm{kmol}) ; R_{g}=$ universal gas constant $(8.314 \mathrm{~J} / \mathrm{mol} \mathrm{K})$, and $T=$ absolute temperature (kelvin). For constant temperature, the ratio of the mass of dissolved air to the absolute air pressure can be given as follows (universal gas law):

$$
\frac{M_{d 0}}{p_{a 0}}=\frac{M_{d t}}{p_{a t}}
$$

where the subscripts 0 and $t$ represent the initial conditions ( $t$ $=0$ ) at any given time, $t$. At a given temperature, the volume of air dissolved in the water phase is independent of either the air or water pressure, as was demonstrated by Fredlund and Rahardjo (1993). For a known joint length $(x)$ per unit width, the change of equivalent air phase height, $\xi_{a d}$ (given in the Appendix) associated with dissolved air may be calculated as follows:

$$
\xi_{a d}=\frac{V_{d a}(t)}{x}
$$

Air can dissolve in water and can occupy approximately $2 \%$ by volume of water (Dorsey 1940). The coefficient of solubility and volumetric coefficient of solubility of different gases for various temperatures was discussed by Dorsey (1940).

\section{Effects of Compressibility of Air}

The compressibility of fluid, particularly air/gas, is a significant factor in modeling two-phase flow through jointed rocks. The compressibility of air at constant temperature with respect to pressure is described by (Fredlund and Rahardjo 1993)

$$
C_{a}=-\frac{1}{V_{a}}\left(\frac{d V_{a}}{d p_{a}}\right)_{t}
$$

where $C_{a}=$ compressibility of air $\left(\mathrm{m}^{2} / \mathrm{N}\right) ; V_{a}=$ volume of air; $p_{a}=$ pressure of air; $t=$ time; $d p_{a}=$ change of air pressure; and $d V_{a}=$ change of air volume. 
For a given joint elemental length, the change of equivalent air-phase height $\xi_{a c}$ (see the Appendix) due to compressibility of air is given by

$$
\xi_{a c}=\frac{C_{a} V_{a} d p_{a}}{x}
$$

\section{Compressibility of Water}

Water has very low compressibility $\left[4.58 \times 10^{-7}(1 / \mathrm{kPa})\right]$ compared to gas $\left[4.94 \times 10^{-3}(1 / \mathrm{kPa})\right]$, and a parameter that is commonly used to characterize the compressibility of water is the bulk modulus $[E=d p /(d v / V)]$. For the analysis presented here, the term compressibility coefficient $\left(C_{w}\right)$ is adopted, where $C_{w}$ $=1 / E$.

Similar to in Eq. (8), the change of the equivalent water-phase height $\xi_{w c}$ (given in the Appendix) due to the compressibility effects of water is given by

$$
\xi_{w c}=\frac{C_{w} V_{w} d p_{w}}{x}
$$

The effect of $\xi_{w c}$ on the height of water phase $h_{w}(t)$ and air phase $h_{a}(t)$ is introduced in the Appendix by two equations. The solution to Eq. (9) is not accurate for air-dissolved water, which inevitably occurs in real discontinuities.

\section{Density of Water and Air}

In two-phase flow, on one hand, the pressure changes caused by the deformation of joint walls or inlet velocity of air will generally induce density changes, which in turn will affect the flow rate. On the other hand, the temperature changes in the flow, which arise due to originate from changes in kinetic energy associated with the velocity changes will influence the flow quantity. However, in this study, the effects of temperature changes are omitted for simplicity, in which case, the change in density of the air phase at time $t$ is determined by (Fredlund and Rahardjo 1993)

$$
\rho_{a}(t)=\frac{p_{a}(t)}{p_{a}(0)} \rho_{a}(0)
$$

where $\rho_{a}(t)=$ final density of air corresponding to final pressure $p_{a}(t)$; and $\rho_{a}(0)=$ initial density of air at $t=0$.

As a result of air dissolved in water, the water phase can be characterized by the following density term (Fredlund and Rahardjo 1993):

$$
\rho_{w}(t)=\rho_{w}(0)+\left[\frac{V_{d a}(t)}{V_{w}(0)}\right]\left[\frac{p_{d a}(t)}{p_{a}(0)}\right]\left[\rho_{a}(0)\right]
$$

where, $\rho_{w}(t)=$ final density of water that corresponds to final pressure $p_{a}(t) ; p_{a}(0)=$ initial pressure of air in air phase; and $\rho_{w}(0)=$ initial density of water at $t=0$.

Subscripts $a, w$ and $d$ represent air, water, and dissolved air, respectively. For most underground solutions, change in the density of water can be neglected in the absence of extreme changes of temperature and pressure, hence $\rho_{w}(t)=\rho_{w}(0)$. Therefore, the second term in Eq. (11) is considerably smaller than $\rho_{w}(0)$.

\section{Deformation of Joints due to External Stress}

We now deal with evaluation of joint normal displacement $\delta_{n}$ given later in the Appendix and other compressibility terms associated with air and water phases. In order to determine $\delta_{n}$, the aperture variations of discontinuities due to stress changes must be taken into account. Rock discontinuity in reality is comprised of a number of point contacts located spatially within a fracture plane. It is the stress concentrations at point contacts that primarily determine joint deformation. The rock material is considered impermeable, and flow is assumed to be confined within the discontinuities. Moreover, the rock matrix is assumed to be isotropic and linearly elastic, thus obeying Hooke's law.

The aperture of discontinuity, $e_{t}$, at any time is given by

$$
e_{t}=e_{0} \pm \delta_{n}
$$

where, $\mathrm{e}_{0}=$ aperture at time $t=0 ; e_{t}=$ aperture at time $t$; and $\delta_{n}=$ increment in aperture during time interval $t$.

In conventional rock mechanics, the normal and shear deformation components of a joint are given by [Brady and Brown (1993)]

$$
\begin{aligned}
& \delta_{n}=\frac{1}{\mathrm{k}_{n}}\left[\sigma_{1} \cos ^{2} \beta+\sigma_{3} \sin ^{2} \beta\right] \\
& \delta_{\tau}=\frac{1}{\mathrm{k}_{s}}\left[\sigma_{3} \cos ^{2} \beta-\sigma_{1} \sin ^{2} \beta\right]
\end{aligned}
$$

where $\sigma_{1}=$ vertical stress applied to the discontinuity $\left(\mathrm{N} / \mathrm{m}^{2}\right)$; $\sigma_{3}=$ horizontal stress applied to the discontinuity $\left(\mathrm{N} / \mathrm{m}^{2}\right)$; $k_{n}=$ normal stiffness of discontinuity $(\mathrm{Pa} / \mathrm{m}) ; k_{s}=$ shear stiffness of discontinuity $(\mathrm{Pa} / \mathrm{m}) ; \beta=$ orientation of discontinuity (deg); $\delta_{n}=$ normal displacement in aperture of discontinuity $(\mathrm{m})$; and $\delta_{\tau}=$ tangential displacement of discontinuity $(\mathrm{m})$.

This mechanical interpretation of joint behavior is considered appropriate in this model. However, because water pressure acts normal to the joint surface and water is incompressible, it is assumed water pressure will act against the in situ stress applied, which would tend to stiffen the rock mass reaction. In the experimental equipment the fracture is oriented almost vertically, thus the potential for shear displacement of the fracture is diminished. The model would need to be extended to include the impact of factors such as shear displacement, dilation, aperture variation and the development of gouge upon shearing and degradation. The writers acknowledge that this assumption may not be true under all conditions, but for the case in these laboratory tests, the opportunity for significant shear displacement and the behavior associated with it are considered remote. Thus $\delta_{\tau}$ remains unchanged, and Eq. (13a) can be modified to

$$
\delta_{n}=\frac{1}{\mathrm{k}_{n}}\left[\sigma_{1} \cos ^{2} \beta+\sigma_{3} \sin ^{2} \beta-p_{w}\right]
$$

where $p_{w}=$ water pressure within the discontinuity $\left(\mathrm{N} / \mathrm{m}^{2}\right)=p_{a}$ (air pressure) in the current tests.

In reality, $\delta_{n}$ may be a function of both water and air pressure $\left(p_{w}\right.$ and $p_{a}$ ), but, for simplicity, it is assumed that a critical value for $\delta_{n}$ is associated with $p_{w}$ only. It is also assumed that yielding of the rock will not occur, and that elastic conditions will prevail at all times. Knowing the individual components, $\xi_{a d}, \xi_{a c}, \xi_{w c}$, and $\delta_{n}$ from Eqs. (6), (8), (9), and (13c), two equations in the Appendix that represent the height of water and air phases, $h_{w}(t)$ and $h_{a}(t)$, respectively, can be solved.

\section{Physical Laws Applied to Two-Phase Flow}

Once the governing equations for the interface level and for the phase heights of air and water are evaluated, the next task is to evaluate the flow rates (velocities) of each phase through a given discontinuity. Poiseuille's law is best suited for describing laminar 
flow (of both gas and air) through a single smooth fracture (parallel plate), which is represented mathematically by

$$
v_{t}=\frac{e^{2} \rho g}{12 \mu}\left[\frac{1}{\rho g} \frac{\partial p}{\partial x}+\frac{\partial z}{\partial x}\right]
$$

where $v_{t}=$ average velocity vector of fluid inside the fracture $(\mathrm{m} /$ $\mathrm{s}$ ); and $e=$ aperture of discontinuity (m). If the fracture is relatively smooth and roughness is ignored, then the discontinuity aperture $(e)$ is the same as the hydraulic aperture; $\rho=$ fluid density $\left(\mathrm{kg} / \mathrm{m}^{3}\right) ; g=$ gravitational acceleration $\left(\mathrm{m} / \mathrm{s}^{2}\right) ; \mu=$ dynamic viscosity $(\mathrm{Pas}) ; p=$ water pressure $\left(\mathrm{N} / \mathrm{m}^{2}\right) ; z=$ elevation head $(\mathrm{m})$; and $d x=$ flow element length over which drop in head is measured (m).

The effects of gravity on fluid flow through a fracture are negligible over a small length of laboratory specimen compared to the relatively high applied inlet pressure. Therefore, assuming the elevation head $(z)$ is negligible compared to the inlet fluid pressure, aperture $e$ in Eq. (14) can be replaced by the height of water phase $h_{w}(t)$ and give

$$
q_{w}(t)=\frac{h_{w}^{3}(t)}{12 \mu_{w}} \frac{d p}{d x}
$$

where $h_{w}(t)=F_{\mathrm{I}}(x, y)_{0}-F_{B}(x, y)_{0}-\xi_{w c}$ (given in the Appendix); $d p / d x=$ pressure gradient along the specimen $(\mathrm{Pa} / \mathrm{m})$; and $q=$ flow rate $\left(\mathrm{m}^{3} / \mathrm{s}\right) /$ meter width.

In the same manner, for the air phase, the Eq. (15) can be written as

$$
q_{a}(t)=\frac{h_{a}^{3}(t)}{12 \mu_{a}} \frac{d p}{d x}
$$

in which $h_{a}(t)=F_{T}(x, y)_{0}-F_{\mathrm{I}}(x, y)_{0}-\left(\delta_{n}+\xi_{a d}+\xi_{a c}-\xi_{w c}\right)$, as defined in the Appendix. From Eqs. (15) and (16), $q_{w}(t)$ and $q_{a}(t)$ are computed, and then compared with laboratory data, explained in, "Experimental Verification."

\section{Experimental Verification}

High-pressure triaxial equipment was initially designed for testing rock specimens under fully saturated conditions (Indraratna and Haque 1999). The writers have modified this equipment to handle two-phase flow that consists of water and air through fractured rock specimens. The testing is carried out using this two-phase high-pressure triaxial apparatus (TPHPTA) for a specimen with vertical fracture. The equipment is capable of accommodating samples with diameters of 45-55 $\mathrm{mm}$ and maximum lengths of $120 \mathrm{~mm}$. The triaxial cell has a maximum confining pressure capacity of $150 \mathrm{MPa}$, which is applied by a hydraulic pump. Testing of fluid flow through a horizontal fracture is not possible using this apparatus, because the fluid flow is directly measured at the top of the specimen. The effects of gravity on fluid flow through a vertical fracture are negligible over the small length of the specimen compared to the magnitude of the drop in pressure (i.e., inlet pressure minus outlet pressure). Therefore, the theory developed for a horizontal fracture (in the Appendix) can still be used as a comparison with the laboratory results.

For a given rock sample in which the fracture is vertical, the equipment can measure inlet air and inlet water pressures independently at the bottom of the sample and the pressure of the mixed flow at the top of the specimen. The inlet fluid pressures are measured using pressure transducers to within accuracy of 0.5 $\mathrm{kPa}$. For this, a pressurized (15 $\mathrm{MPa})$ gas reservoir and water reservoir are also provided. Moreover, axial and diametric deformations as well as the volume change of the sample are measured. The axial load is applied to the top of the sample by a shaft using a servo-controlled Instron machine at strain rate of 0.001 $\mathrm{mm} / \mathrm{min}$. Diametric deformation and volume changes of the sample are recorded by an assembly that consists of a strain meter and a LVDT which is connected to the volume measurement device. In order to measure the mass of water and volume of air flowing through the sample, a sensitive electronic weighing scale and a fully automated film flowmeter are used. The film flowmeter can measure nondissolvable gas ranging from $0.2 \mathrm{~mL} / \mathrm{min}$ to $50 \mathrm{~L} / \mathrm{min}$.

\section{Experimental Procedure}

The samples were tested in the manner described elsewhere (Indraratna and Ranjith 2001). Joint surfaces were mapped using a profilometer to estimate the joint roughness coefficient (JRC). The estimated JRC values for the specimens tested are between 2 and 4, which verifies that the joint is smooth and planar (Barton and Choubey 1976). This was necessary to validate the assumption of stratified flow and laminar flow conditions.

In order to measure single-phase (i.e., fully saturated) permeability and two-phase permeability (i.e., partially saturated), permeating fluids were applied to the sample as follows: (1) water flow only, fully saturated with water (single phase); (2) air flow only, completely dry (single phase); and (3) water and air, partially saturated (two phase). In all three cases, the flow measurements were taken at the same confining pressures for direct comparison.

Two-phase flow was simulated as follows. The jointed rock specimen was initially saturated with water, and a steady state flow of water was observed. Subsequently, air was injected, and the air and water pressures applied were maintained at $250 \mathrm{kPa}$. Once the system reached equilibrium, the volume of air and mass of water was recorded. The experiment was repeated for different cell pressures to observe the quantities of both single-phase flow and two-phase flow.

\section{Results and Discussion}

Most single-phase flow models in geotechnical engineering are based on laminar flow conditions, such as simplified Darcy law. Since the flow pattern assumed in this study is stratified, and because the joint surface is relatively smooth (JRC of $0.2-2.5$ ), the flow expected is laminar. Therefore, the theoretical prediction for steady state laminar flow (for both air and water) through a smooth joint was carried out on the basis of the mathematical model described earlier. The material properties of the rock and fluids are presented in Table 1. The heights of the air phase and water phase strongly depend on normal deformation of the joint. For different normal stresses, the predicted normal deformation [Eq. $(13 c)]$ and the measured normal deformation are shown in Fig. 4. Curve A shows normal deformation based on Eq. (13c), where the normal joint stiffness was calculated from uniaxial test data in which the axial load was applied normal to the surface of horizontal fracture, and deformations of the mechanical aperture were measured for various axial loads. In contrast, curve B, also based on Eq. $(13 c)$, with the normal joint stiffness $\left(k_{n}\right)$ determined from triaxial data in which the confining pressure (i.e., stress normal to the vertical joint) and axial load were applied to the specimen and deformation of the fracture for various confining pressures was measured by clip gauges. The data indicate a significant reduction in normal deformation in curve B in com- 
Table 1. Fluid Properties and Relevant Model Parameters

\begin{tabular}{|c|c|c|}
\hline Parameter & Value & Unit \\
\hline $\begin{array}{l}\text { Coefficient of compressibility of water, } \\
C_{w} \text { at } 20^{\circ} \mathrm{C} \text { for } 1 \mathrm{~atm}\end{array}$ & $4.49 \times 10^{-5}$ & $1 / \mathrm{atm}$ \\
\hline Viscosity of water, $\mu_{w}$ & $1.12 \times 10^{-3}$ & $\mathrm{Pas}$ \\
\hline Density of water $\rho_{w}$ & 1,000 & $\mathrm{~kg} / \mathrm{m}^{3}$ \\
\hline Density of air, $\rho_{a}$ at $20^{\circ} \mathrm{C}$ & 1.23 & $\mathrm{~kg} / \mathrm{m}^{3}$ \\
\hline Viscosity of air, $\mu_{a}$ & $1.79 \times 10^{-5}$ & $\mathrm{~Pa} \mathrm{~s}$ \\
\hline $\begin{array}{l}\text { Volumetric coefficient of solubility } \\
\text { of water, } V_{d t}\end{array}$ & 0.01868 & No unit \\
\hline Maximum pore air pressure, $p_{a}$ & 250 & $\mathrm{kPa}$ \\
\hline Maximum pore water pressure, $p_{w}$ & 250 & $\mathrm{kPa}$ \\
\hline Atmospheric pressure, $p_{\text {atm }}$ & 100 & $\mathrm{kPa}$ \\
\hline Average density of rock, $\rho_{\text {rock }}$ & 2,760 & $\mathrm{~kg} / \mathrm{m}^{3}$ \\
\hline $\begin{array}{l}\text { Joint roughness coefficients for planar } \\
\text { fractures }\end{array}$ & $0.4-2.5$ & \\
\hline Initial joint aperture, $e_{\text {initial }}$ & 64 & $\mu \mathrm{m}$ \\
\hline Mean fracture aperture & 100 & $\mu \mathrm{m}$ \\
\hline Interfacial friction factor, $f_{\mathrm{I}}$ & 0.014 & \\
\hline $\begin{array}{l}\text { Variation in normal stress (acting on joint) } \\
\text { for phase height estimation }\end{array}$ & $0.5-5$ & $\mathrm{MPa}$ \\
\hline $\begin{array}{l}\text { Maximum normal stress at residual } \\
\text { aperture }\end{array}$ & 8 & $\mathrm{MPa}$ \\
\hline $\begin{array}{l}\text { Reynolds number for laminar, single-phase } \\
\text { water flow through joint }\end{array}$ & $<100$ & \\
\hline $\begin{array}{l}\text { Reynold number for laminar, single-phase } \\
\text { air flow through joint }\end{array}$ & $<500$ & \\
\hline
\end{tabular}

parison with in curve A. This is because in the triaxial test, where there is confining pressure, normal deformation is expected to be less. Also, from the measured fluid flow data, the hydraulic apertures of the joint could be backcalculated for a given confining stress using a cubic relation [Eq. (15)]. Each data point plotted (curve C) represents the average of at least two tests. The sudden drop in normal deformation at $1.5 \mathrm{MPa}$ is probably due to experimental error. In general, curve C, predicted by Eq. (15), is in

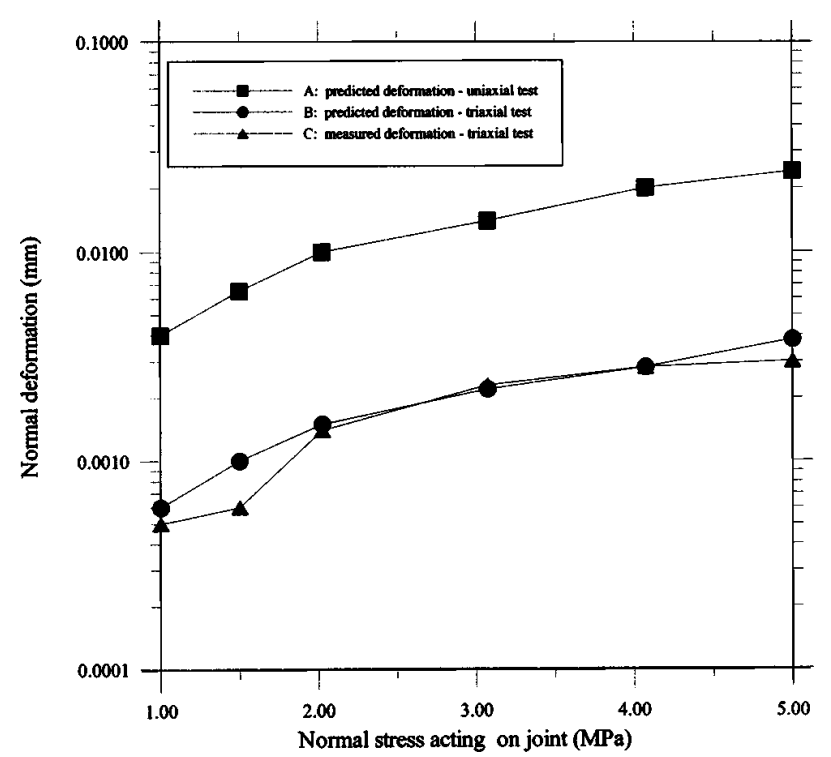

Fig. 4. Measured and predicted normal deformation of jointed rock specimen for various normal stress levels

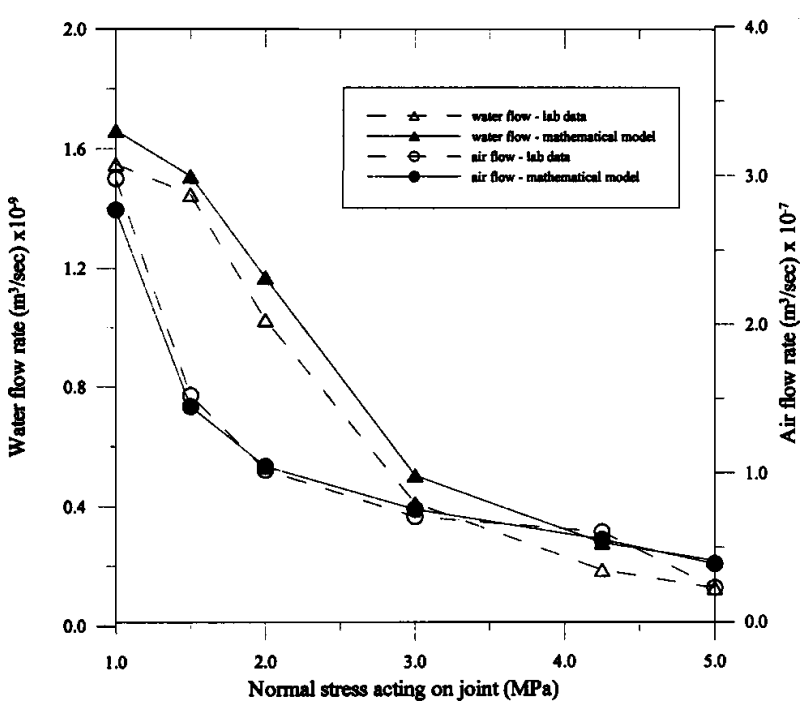

Fig. 5. Flow rate of each phase for different confining stresses

agreement with the triaxial data, whereas normal deformation represented by curve $\mathrm{A}$ is overestimated. Therefore, in this study, the behavior modeled by curve $\mathrm{B}$ has been incorporated into verification of the mathematical model.

The predictions obtained from the proposed two-phase model are compared with experimental data in Figs. 5-10. The flow rate of each phase was observed under the laminar flow condition as explained below. For a given confining pressure (i.e., normal stress applied to the joint) and axial stress, the flow rate of each phase was measured for different inlet pressures, and the corresponding flow rates were plotted against the inlet fluid pressure. It is observed that a significant linear range exists initially that represents laminar flow. Turbulent flow occurs (nonlinearly) only at very high inlet pressure. The calculated and measured flow rates of each phase for different confining pressures are shown in Fig. 5 based on Eqs. (15) and (16). Like in the single-phase situation, flow quantities of both phases decreased with an increase in confining pressure. When the confining stress is increased from 1.0 to 5.0 $\mathrm{MPa}$, the air flow rate and the water flow rate diminish by more than $80 \%$ due to the crack closure. The rate of decrease in flow volume tends to become marginal at higher levels of stress as the joint apertures approach their residual values (i.e., with confining stress $>5 \mathrm{MPa}$ ). The measured air flow rate is slightly smaller than the calculated values, which is probably due to some air being trapped in pores or along the joint walls in the form of a thin layer of film.

A comparison of single-phase and two-phase flow rates for different confining pressures is shown in Fig. 6. It can be observed that the flow rates of both water and air significantly decrease when air enters a joint that is already filled with water. Due to the comparative differences in viscosity, water is expected to flow like film along the joint with air tending to occupy the majority of the total aperture, thereby contributing to a significant reduction in the water flow rate. In two-phase flows, the water and air flow rates are about $85 \%$ less than in corresponding singlephase flows at the same confining pressure. Moreover, as indicated in Fig. 6, both the air and water flow rates in two-phase flow diminish as the confining pressure is increased. However, the air flow decreases at a much faster rate for the same increase in confining stress. Equivalent phase levels of water $h_{w}(t)$ and air $h_{a}(t)$, joint deformation due to normal stress $\delta_{n}$, and the equiva- 


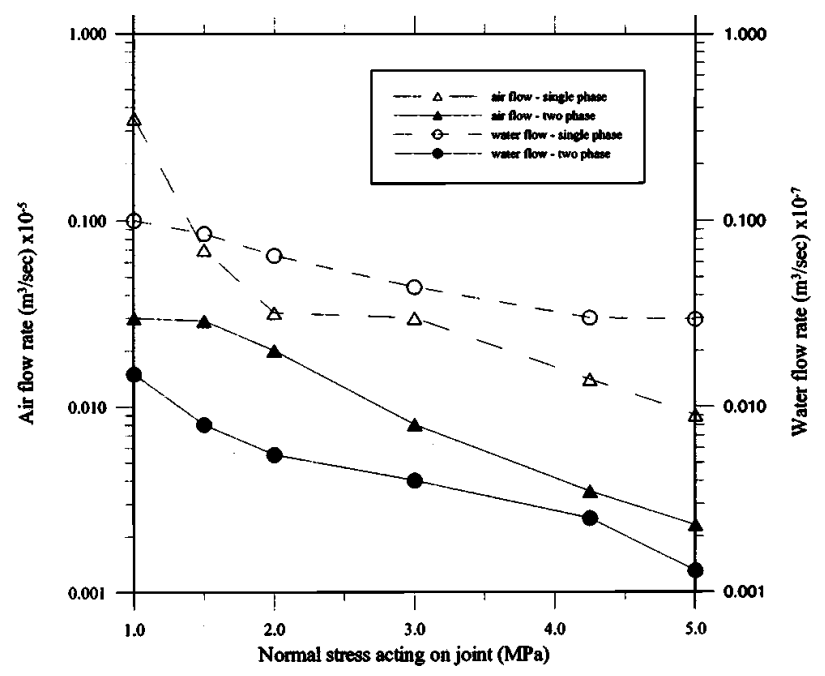

Fig. 6. Comparison of single- and two-phase flows for different confining stresses

lent heights of air, $\xi_{\text {ad }}$, and $\xi_{\text {ac }}$ (based on solubility and compressibility, respectively) are plotted in Fig. 7. Total deformation of the joint wall is composed of these equivalent phase levels. Almost 95\% of the magnitude of $h_{a}(t)$ and $h_{w}(t)$ is due to normal joint deformation $\left(\delta_{n}\right)$, the rest being the combined effect of $\xi_{a c}$ and $\xi_{a d}$. As expected, the contribution of $\xi_{\mathrm{ac}}$, the air compressibility, is more significant than that of solubility component $\xi_{a d}$. While $\xi_{a c}$ amounts to about $4-5 \%$ of the value of $\delta_{n}$, the magnitude of $\xi_{a d}$ is not more than $0.01 \%$ of $\delta_{n}$. At large confining pressures $(>5 \mathrm{MPa})$, a further decrease in $\delta_{n}$ may be marginal once the joint aperture reaches its residual values. Beyond this stage, the role $\xi_{a c}$ and $\xi_{a d}$ will become increasingly pronounced.

The joint hydraulic apertures based on the model and laboratory results are plotted versus the confining stress in Fig. 8. The individual steady state flow components of air and water were used to estimate joint apertures based on laboratory data (dashed lines). It is verified that the discrepancy between the air-based and

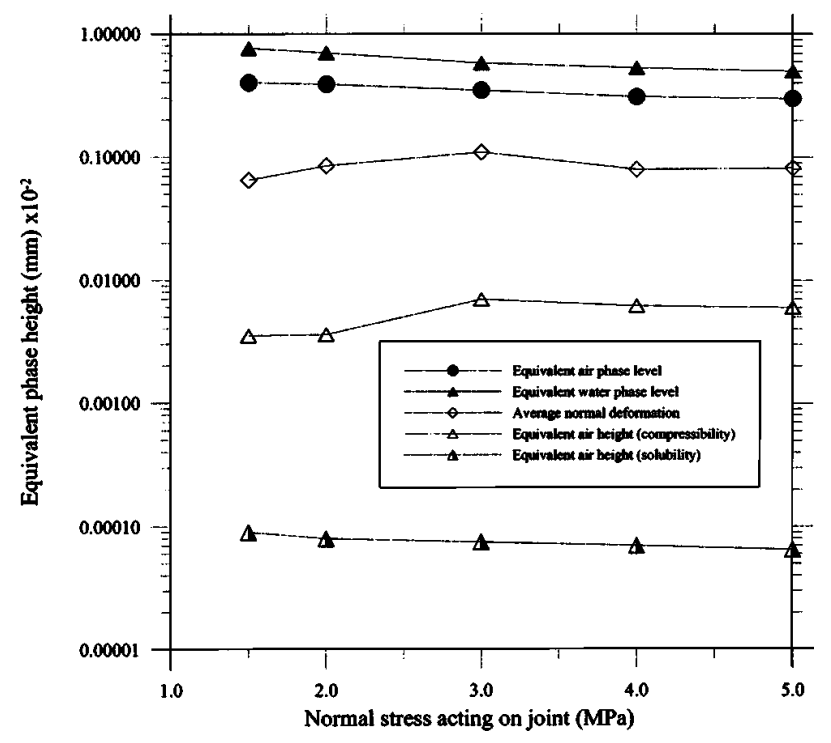

Fig. 7. Equivalent phase heights of water and air

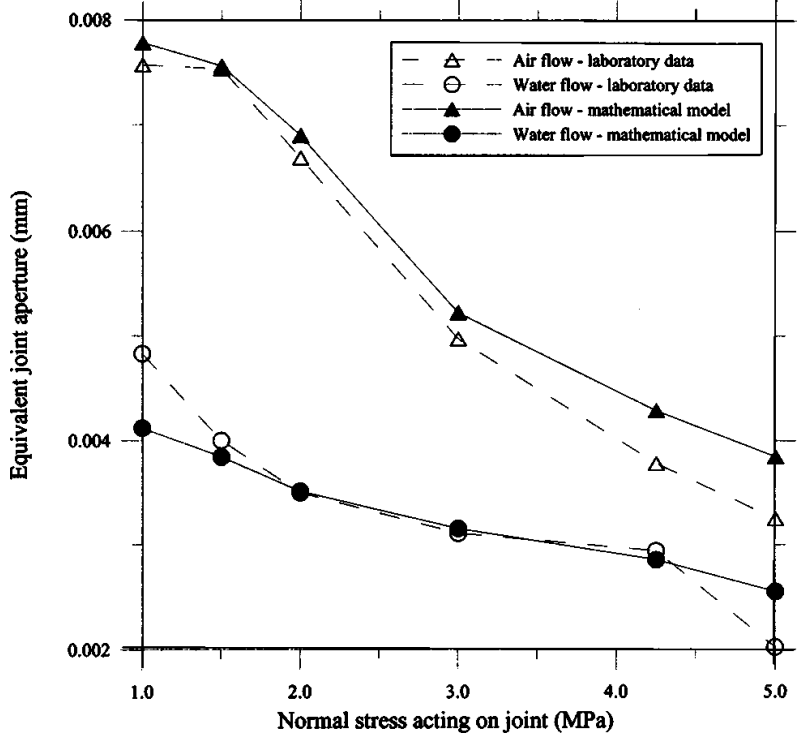

Fig. 8. Equivalent joint aperture for various confining stresses

water-based apertures decreases significantly at elevated confining pressures once the joint apertures approach their residual values. It also follows that air will occupy most of the joint at low confining stress. In other words, like in conventional multiphase flow in pipes, a higher air flow rate is expected for larger apertures. The model predictions (solid lines, Fig. 9) are generally in acceptable agreement with the laboratory data. Fig. 9 shows the predicted and measured permeability of each fluid phase versus the steady state flow rate through the rock specimen for different levels of confining stress. Here, the fracture permeability was calculated using the term $e^{2} / 12$ for a hydraulic aperture $e$ assuming that the matrix permeability is negligible. As indicated in Fig. 9 , the fracture permeability decreases with an increase in confining stress. The decrease in fracture permeability with respect to air, however, is greater than that of water. It is important to note that it is usual to give units of fracture permeability in $\mathrm{m}^{2}$.

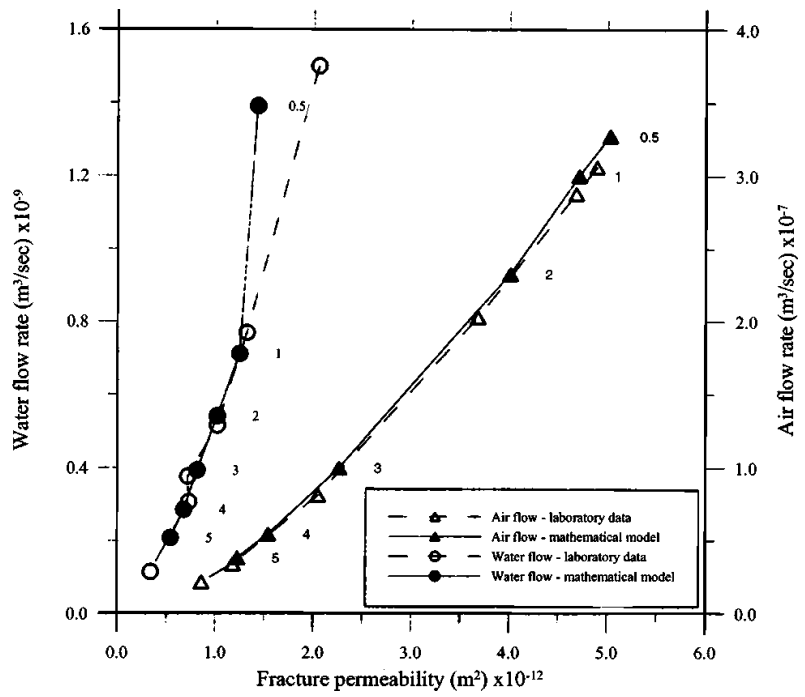

Fig. 9. Two-phase permeability of water and air for confining stress between 0.5 and $5 \mathrm{MPa}$ 


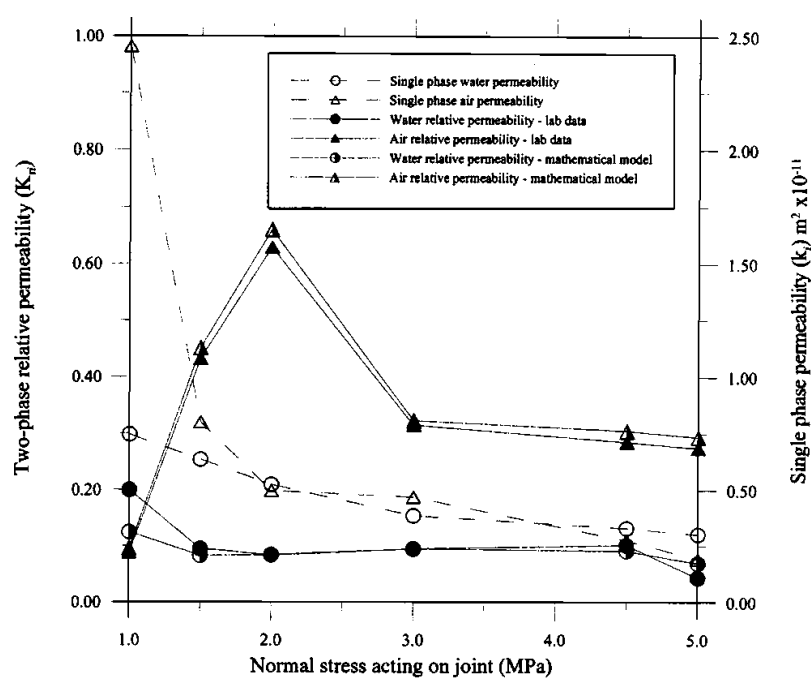

Fig. 10. Relative permeability of each phase for different confining stresses

From a geotechnical point of view, the commonly used approach to describe the two-phase flow through fractures is generalized Darcy law. In multiphase flow analysis, it is convenient to introduce the term "relative permeability" in the Darcy equation, as explained below.

Given a fracture area, $A$, for the water phase

$$
q_{w}=\frac{A k K_{r w}}{\mu_{w}}\left(\frac{d p}{d x}+\rho_{w} g \frac{d z}{d x}\right)_{w}
$$

where $k=$ intrinsic fracture permeability based on single-phase flow. This depends on the fracture geometry and material properties, properties of permeating fluids, and interconnection of the discontinuities. The magnitude of $k$ is estimated from singlephase flow, which $=e^{2} / 12$, where $e=$ hydraulic aperture; $d p / d x=$ pressure gradient along the joint; $\rho_{w}=$ density of water $\left(\mathrm{kg} / \mathrm{m}^{3}\right) ; d z / d x=$ elevation head gradient along the joint; and $\mu_{w}=$ dynamic viscosity of water (Pas).

Similarly, for the air phase

$$
q_{a}=\frac{A k K_{r a}}{\mu_{a}}\left(\frac{d p}{d x}+\rho_{a} g \frac{d z}{d x}\right)_{a}
$$

where $\mu_{a}=$ dynamic viscosity of air $(\mathrm{Pas}) ; \rho_{a}=$ density of air $\left(\mathrm{kg} / \mathrm{m}^{3}\right)$; and $K_{r a}$ and $K_{r w}=$ relative permeability of air and water, respectively.

These depend on properties of permeating fluids such as the solubility and compressibility of one phase on the other for different levels of stress, and inlet pressures and the temperature of each phase.

From the rock samples given, the hydraulic aperture is estimated for single-phase flow (i.e., for water and air separately) at a given confining pressure and inlet fluid pressure. Under the same confining stress and inlet air and water pressures, two-phase steady state flow is monitored. Using Eqs. (17) and (18), $K_{r w}$ and $K_{r a}$ can be computed for a given range of confining (normal) pressures (Fig. 10). $K_{r a}$ increases with an increase in confining stress up to $2 \mathrm{MPa}$, and then decreases to a constant value of about 0.3 beyond $3 \mathrm{MPa}$. As explained earlier (Fig. 6), below a confining pressure of $2 \mathrm{MPa}$, the single-phase air flow volume is much greater than the two-phase air volume, and this results in reduced values of permeability, $K_{r a}$. However, at $2 \mathrm{MPa}$, the single-phase air flow volume significantly decreased to an almost steady value, hence increased relative permeability results as indicated by the peak value of $K_{r a}$ in Fig. 10. In contrast, beyond 2 $\mathrm{MPa}$ confining pressure, the rate of decrease in two-phase flow is more significant than that in single-phase flow (Fig. 6), which explains the subsequent reduction of $K_{r a}$ a shown in Fig. 10. For the water phase, relative permeability $K_{r w}$ decreases continuously as the confining stress is increased, unlike in the case of $K_{r a}$ which increases initially up to $2 \mathrm{MPa}$ and then decreases. This is because, unlike in fully saturated air flow, fully saturated water flow does not decrease significantly with an increase in confining pressure. Comparison of the model predictions with laboratory measurements indicates good agreement; hence the ability of the proposed model to predict two-phase flow conditions in a single fracture is verified.

In order to predict the unsaturated flow through a jointed rock mass to a subsurface cavity, the relative permeability concept can be incorporated into a numerical model. One possible application of this concept is at underground nuclear waste disposal plants, where contaminated (radioactive) unsaturated flow can migrate towards the groundwater table.

\section{Conclusions}

This study was concerned with a theoretical and experimental investigation of two-phase flow of water and air in a single rock joint. The model developed represents a preliminary attempt to model two-phase flow behavior under simplified conditions that involve stratified flow conditions. The close similarity between the measured and the predicted results suggests that the assumptions made in the model are valid over a range of hydromechanical conditions. However, the writers acknowledge the obvious limitations of this preliminary model and the flow pattern assumed in trying to extend the model to more general rock engineering conditions.

In the analytical approach, governing equations were developed to model the behavior of a joint filled with water and air, that considered the effects of normal deformation of the joint, the compressibility of air and water, and the solubility of air in the water phase. For this particular model, the role of capillary pressure in the two-phase flow behavior of the mixture was ignored. As explained previously, this was considered reasonable since the fracture apertures were relatively large and the hydraulic gradients used in these experiments were about 20 times the calculated average capillary pressure. Explicit solutions were determined for an inclined joint with parallel walls, within which the air and water phases travel as stratified layers. Experimental data based on triaxial testing were acquired for a fractured rock specimen at different confining pressures. The measured flow rate of the water phase was found to be almost equal to the calculated flow rate. However, for the flow rate of air, slight deviation from theory was encountered, which was probably due to some discontinuous air pockets trapped within the rock matrix.

In two-phase flow, the flow rate of both air and water decreases when the confining pressure is increased. The flow rates of both phases decrease by as much as $80 \%$ when the confining pressure exceeds $5 \mathrm{MPa}$, which is mainly due to reduction of the aperture by joint deformation. Under the same conditions of confining pressure and inlet pressure, two-phase flow rates are much smaller than the corresponding single-phase flow rates. For example, at $3 \mathrm{MPa}$ confining pressure, both the water flow and air flow rates decrease by more than $75 \%$ from corresponding singlephase flows at similar inlet pressures. 
It is normal joint deformation that contributes most to the change in phase level of air and water layers, while the effects of air solubility and compressibility components are relatively small. Nevertheless, at significantly elevated confining pressures, at which the joint apertures have reached their residual values, the effects of compressibility and solubility of air in water become increasingly more pronounced. At a lower range of confining stress $(0-2 \mathrm{MPa})$, the variation of relative permeability of both air and water is generally nonlinear. However, once the joint apertures approach their residual values (beyond $3 \mathrm{MPa}$ ), the value of the relative permeability with confining pressure can be modeled by a linear relationship at higher confining pressure. It is evident that the flow through a fractured sample is not always stratified. Nevertheless, the computed water and air phase heights, i.e., $h_{w}(t)$ and $h_{a}(t)$, introduced by the writers in the current model give a realistic prediction of flow volumes, as verified by the laboratory measurements. The study confirms that the analytical model can accurately predict the flow rates of both air and water phases in a single joint for given applied stress conditions. The practical implications of this work are seen for application to underground construction where unsaturated groundwater conditions may occur or to mining where, say, coal is being extracted close to bodies of natural water or beneath large aquifers.

\section{Acknowledgments}

The writers acknowledge the efforts of Alan Grant (laboratory technician) during the testing program, and the financial support given to the project by Strata Control Technology Pty. Ltd. (Wollongong) and the Australian Research Council. The writers appreciate the efforts of Dr. Hadi Khabbaz for a final check of all mathematical derivations.

\section{Appendix: Development of Two-Phase Flow Constitutive Equations}

It is suggested that two-phase flow through a single rock joint can be analyzed by reformulating the momentum conservation equation, previously done by Wallis (1969), to include the effect of in situ stress conditions and joint inclination. Based on the unit width of a rock element, for water flow only (in situ stress not considered here):

$$
\begin{gathered}
\left(\rho_{w} v_{w} A_{w}\right) \frac{d v_{w}}{d x}-\left(\rho_{w} A_{w}\right) \frac{d v_{w}}{d t}-\left(A_{w}\right)\left(\frac{d p}{d x}\right)_{w}-\left(\rho_{w} g \sin \beta A_{w}\right) \\
+\left(\tau_{w a} S_{w a}\right)-\left(\tau_{j w} S_{j w}\right)-\left(v_{a}-v_{w}\right)(1-\eta) M \frac{d R}{d x}=0
\end{gathered}
$$

where $a=$ subscript that represents air phase; $w=$ subscript that represents water phase; $A_{i}=$ cross sectional area of fluid $i\left(\mathrm{~m}^{2}\right)$; $\rho=$ density of fluid $\left(\mathrm{kg} / \mathrm{m}^{3}\right) ; v=$ velocity of fluid at time $t(\mathrm{~m} / \mathrm{s})$; $d x=$ length of fluid element (m) along the joint length, $x ; y=$ width of fluid element (m), later assumed the unit width; $S_{w a}=$ air-water interface perimeter $=y(\mathrm{~m}) ; S_{j w}=$ length of fracture perimeter in contact with the water phase $=2 h_{w}+y(\mathrm{~m})$; and $\tau_{w a}=\left[f_{\mathrm{I}}\left(v_{a}-v_{w}\right)^{2} \rho_{a} / 2\right]=$ shear stress acting on the water-air interface $\left(\mathrm{N} / \mathrm{m}^{2}\right)$. It is convenient to express the interfacial and joint wall shear stress in terms of friction factors (Taitel and Dukler 1976), where $f_{I}$ is the friction factor between two phases: $\tau_{j w}$ $=f_{w} \rho_{w} v_{w}^{2} / 2=$ shear stress acting on the wall $\left(\mathrm{N} / \mathrm{m}^{2}\right)$, where $f_{w}=$ friction factor between the wall and water; $f_{k}=c(\mathrm{R})^{-n}$, where $\mathrm{R}$ is the Reynolds number determined by $(\mathrm{R})_{k}$ $=4 v_{k} A_{k} \rho_{k} / S_{k} \mu_{k}$, where $k$ takes $a$ and $w$ for air and water, respectively. Note that typical friction coefficients, $c=0.0046$ and $n=0.2$ for turbulent flow and $c=16$ and $n=1$ for laminar flow may be assumed (Cohen and Hanratty 1968).

Similarly, for the air phase (subscript $a$ represents the air phase):

$$
\begin{gathered}
\left(\rho_{a} v_{a} A_{a}\right) \frac{d v_{a}}{d x}-\left(\rho_{a} A_{a}\right) \frac{d v_{a}}{d t}-\left(A_{a}\right)\left(\frac{d p}{d x}\right)_{a}-\left(\rho_{a} g \sin \beta A_{a}\right) \\
-\left(\tau_{w a} S_{w a}\right)-\left(\tau_{j a} S_{j a}\right)-\left(v_{a}-v_{w}\right) \eta M \frac{d R}{d x}=0
\end{gathered}
$$

where $S_{j a}=$ length of fracture perimeter in contact with air phase $=2 h_{a}+y(\mathrm{~m}) ; \tau_{j a}=f_{a} \rho_{a} v_{a}^{2} / 2=$ shear stress acting on wall $\left(\mathrm{N} / \mathrm{m}^{2}\right)$; and $f_{a}=$ friction factor between the joint wall and air, which depends on the Reynolds number determined for air.

Eqs. (19) and (20) can be further extended to incorporate the phase heights of water and air in stratified flow, as well as to model factors that influence these phase heights. The crosssectional area of the water phase may be written in terms of the phase level $\left(h_{w}\right)$ and width of the wetted joint wall $(y)$. In nature, rock fractures can extend for considerable distances and occupy large surface areas. In the case of the fractures used in the test specimens the fracture surface area of each joint wall is approximately the product of the sample height and width $\left(0.00594 \mathrm{~m}^{2}\right)$. The perimeter of the fracture in contact with the air and water phases can be simplified if the phase level component $\left(h_{w}\right.$ or $\left.h_{a}\right)$ is neglected (introduces an error of $<0.05 \%$ even when the fracture is fully saturated, assuming a $10 \mu \mathrm{m}$ aperture). The perimeter length of the interface and the joint walls can be then be assumed to be approximately the same (i.e., $S_{w a}=S_{j a}=S_{j w}$ ) as the width across the flow. When capillary forces are negligible (compared to viscous forces) the pressure gradient in both phases are equal [i.e., $\left.(d p / d x)_{w}=(d p / d x)_{a}=(d p / d x)\right]$. Eliminating the drop in pressure $(d p / d x)$ from the above two equations in order to attain a solution for the interface level, and assuming unit width (i.e., $y$ $=1$ ),

$$
\begin{aligned}
\frac{1}{h_{w}(t)} & {\left[\tau_{w a}-\tau_{j w}-\left(v_{a}-v_{w}\right)(1-\eta) M \frac{d R}{d x}\right] } \\
+ & \frac{1}{h_{a}(t)}\left[\tau_{w a}+\tau_{j a}+\left(v_{a}-v_{w}\right) \eta M \frac{d R}{d x}\right] \\
= & -\rho_{w} v_{w} \frac{d v_{w}}{d x}+\rho_{a} v_{a} \frac{d v_{a}}{d x}+\rho_{w} \frac{d v_{w}}{d t}-\rho_{a} \frac{d v_{a}}{d t} \\
& -g \sin \beta\left[\rho_{a}-\rho_{w}\right]
\end{aligned}
$$

where $M$ is now considered the total mass flow $(\mathrm{kg} / \mathrm{s})$ for unit width.

The mechanical and hydraulic behavior of discontinuities in rocks depends strongly on the topography of the contacting surfaces and the degree of correlation between them. The topography of joint walls has been studied using various techniques including profilometers (Brown and Scholz 1985; Pyrak-Nolte et al. 1987). The initial surface profiles of top and bottom joint walls are taken as $F_{T}(x, y)_{0}$, and $F_{B}(x, y)_{0}$, respectively. Once they are subjected to deformation associated with external stress and fluid pressure, they are assumed to take the form of $F_{T}(x, y)_{t}$, and $F_{B}(x, y)_{t}$, respectively, after time, $t$. The interface between the two phases is described by $F_{I}(x, y)_{0}$, and $F_{I}(x, y)_{t}$ at $t=0$ and 
after time $t$, respectively. The heights of the water and air phases at time $t$ are defined by the following equations:

$$
\begin{aligned}
& h_{w}(t)=F_{I}(x, y)_{t}-F_{B}(x, y)_{t} \\
& h_{a}(t)=F_{T}(x, y)_{t}-F_{I}(x, y)_{t}
\end{aligned}
$$

If $\xi_{w c}$ is the change in interface between two phases due to the compressibility of water, then the height of the water phase, $h_{w}(t)$, can be represented by

$$
h_{w}(t)=F_{I}(x, y)_{0}-F_{B}(x, y)_{0}-\xi_{w c}
$$

or

$$
h_{w}(t)=F_{I}(x, y)_{0}-F_{B}\left(x, y, \Delta_{B}\right)_{t}
$$

where $F_{B}\left(x, y, \Delta_{B}\right)_{t}$ is given by the expression $F_{B}(x, y)_{0}+\xi_{w c}$.

Factors which control the height of the air phase are mechanical deformation of the joint, the compressibility of air, the rate of solubility of air in water, and effects of changes in fluid property and temperature. The height of the air phase, $h_{a}(t)$, at time $t$ is given by

$$
h_{a}(t)=F_{T}(x, y)_{0}-F_{I}(x, y)_{0}-\Delta_{T}
$$

where $\Delta_{\mathrm{T}}=$ deformation of the wet wall in contact with the air phase. The total deformation, $\Delta_{T}$, includes the effects of the compressibility of water $\left(\xi_{w c}\right)$, compressibility of air $\left(\xi_{a c}\right)$, solubility of air in water $\left(\xi_{a d}\right)$, and elastic deformation of the joint wall $\left(\delta_{n}\right)$ on the height air phase $h_{a}(t)$. Hence,

$$
\Delta_{T}=\xi_{a c}+\xi_{a d}+\delta_{n}-\xi_{w c}
$$

If $F_{T}\left(x, y, \Delta_{T}\right)$ is represented by the $F_{T}(x, y)_{0}-\Delta_{T}$, Eq. (23) can be rewritten as

$$
h_{a}(t)=F_{T}\left(x, y, \Delta_{T}\right)-F_{I}(x, y)_{0}
$$

Substituting Eqs. (22) and (25) into Eq. (21) yields

$$
\begin{aligned}
\left\{\tau_{w a}[\right. & F(x, y, \Delta)]-\left[\tau_{j w}\right] F_{T}\left(x, y, \Delta_{T}\right)-\tau_{j a} F_{B}\left(x, y, \Delta_{B}\right) \\
& -\left(v_{a}-v_{w}\right)(1-\eta) M \frac{d R}{d x}\left[(1-\eta) F_{T}\left(x, y, \Delta_{T}\right)\right. \\
& \left.\left.+\eta F_{B}\left(x, y, \Delta_{B}\right)\right]+F_{I}(x, y)_{0}\left[\tau_{j w}+\tau_{j a}+\left(v_{a}-v_{w}\right) M \frac{d R}{d x}\right]\right\} \\
= & \left\{F_{I}(x, y)_{0}\left[F_{T}\left(x, y, \Delta_{T}\right)+F_{B}\left(x, y, \Delta_{B}\right)\right]-F_{I}^{2}(x, y)_{0}\right. \\
& \left.-F_{T}\left(x, y, \Delta_{T}\right) F_{B}\left(x, y, \Delta_{B}\right)\right\}\{A\}
\end{aligned}
$$

where

$$
\begin{aligned}
& F(x, y, \Delta)=F_{T}\left(x, y, \Delta_{T}\right)-F_{B}\left(x, y, \Delta_{B}\right) \\
& A=\left[B-g \sin \beta\left(\rho_{a}-\rho_{w}\right)\right] \\
& B=\left(-\rho_{w} \mathrm{v}_{\mathrm{w}} \frac{d v_{w}}{d x}+\rho_{a} v_{a} \frac{d v_{a}}{d x}+\rho_{w} \frac{d v_{w}}{d t}-\rho_{a} \frac{d v_{a}}{d t}\right) \\
& =\text { force per unit area associated with unsteady effects } \\
& \text { of flow. }
\end{aligned}
$$

The above expression can be rearranged into the following simpler form:

$$
\begin{aligned}
& F_{I}(x, y)_{0}\left[A \sum_{k=1}^{2} \Delta_{k}-\sum_{i=a, w} \tau_{j i}-C\right]-A F_{I}^{2}(x, y)_{0} \\
& =F(x, y, \Delta) \tau_{w a}-\left[\sum_{\substack{k=1 \\
i=\mathrm{a}, \mathrm{w}}}^{2} \tau_{j i} \Delta_{k}\right]-C\left[(1-\eta) \Delta_{1}+\eta \Delta_{2}\right] \\
& \quad+A \Delta_{1} \Delta_{2}
\end{aligned}
$$

where

$$
\begin{gathered}
C=\left[\left(v_{a}-v_{w}\right) M \frac{d R}{d x}\right] \\
\Delta_{1}=F_{T}\left(x, y, \Delta_{T}\right) \\
\Delta_{2}=F_{B}\left(x, y, \Delta_{B}\right)
\end{gathered}
$$

Eq. (27) can also be simplified so the main governing equation is as follows:

$$
F_{I}(x, y)_{0} \Delta_{3}-A F_{I}^{2}(x, y)_{0}-D=0
$$

where

$$
\Delta_{3}=\left[A \sum_{k=1}^{2} \Delta_{k}-\sum_{i=a, w} \tau_{j i}-C\right]
$$

and

$$
D=F(x, y, \Delta) \tau_{w a}-\left[\sum_{\substack{k=1 \\ i=a, w}}^{2} \tau_{j i} \Delta_{k}\right]-\sum_{\substack{k=1 \\ N=1-\eta, \eta}}^{2} C N \Delta_{k}+A \Delta_{1} \Delta_{2}
$$

where

$$
\begin{gathered}
e_{t}=F(x, y, \Delta)=F_{T}\left(x, y, \Delta_{T}\right)-F_{B}\left(x, y, \Delta_{B}\right)=h_{a}(t)+h_{w}(t) \\
\tau_{j i}=\tau_{j i}
\end{gathered}
$$

where $i$ takes subscripts $a$ and $w$ for air and water, respectively.

Eq. (28), which is quadratic, has a definite solution to determine the interface level. A simplified analytical solution for the interface height for steady state flow in a horizontal joint can be obtained by neglecting the effects of gravity associated with the air phase. Eq. (27) will then lead to the following simplified form:

$$
\begin{gathered}
e_{t}\left[\tau_{w a}\right]-\sum_{\substack{k=1 \\
i=a, w}}^{2} \tau_{j i} \Delta_{k}+F_{I}(x, y)_{0} \sum_{i=a, w} \tau_{j i}=0 \\
F_{I}(x, y)_{0}=\frac{\sum_{k=1}^{2} \quad i=a, w}{\tau_{j i} \Delta_{k}-F(x, y, \Delta)\left[\tau_{w a}\right]} \\
\sum_{i=a, w} \tau_{j i} \\
F_{I}(x, y)_{0}=\frac{\tau_{j a} F_{B}\left(x, y, \Delta_{B}\right)+\tau_{j w} F_{T}\left(x, y, \Delta_{T}\right)-\tau_{w a} e_{t}}{\tau_{j a}+\tau_{j w}}
\end{gathered}
$$

Eq. (31) models the interface between air and water phases for steady state flow through a single horizontal joint.

\section{References}

Barton, N., and Choubey, V. (1976). "The shear strength of rock joints in theory and practice." Rock Mech., 10, 1-54.

Brady, B. H. G., and Brown, E. T. (1993). Rock mechanics for underground mining, 2nd Ed., Chapman and Hall, London.

Brown, S. R. (1987). "Fluid flow through rock joints: The effect of surface roughness." J. Geophys. Res., 92, 1337-1347.

Brown, S. R., and Scholz, C. H. (1985). "Broadband study of the topography of natural rock surfaces." J. Geophys. Res., 90, 12575-12582. 
Cohen, S. L., and Hanratty, T. J. (1968). "Effects of waves at a gasliquid interface on a turbulent air flow." J. Fluid Mech., 31, 467-469.

Dorsey, N. E. (1940). Properties of ordinary water substances, American Chemical Society, Reinhold, New York.

Fourar, M., and Bories, S. (1995). "Experimental study of air-water twophase flow through a fracture (narrow channel)." Int. J. Multiphase Flow, 21, 621-637.

Fourar, M., Lenormand, R., and Persoff, P. (1993). "Two-phase flow in smooth and rough fractures: Measurement and correlation by porousmedium and pipe flow models." Water Resour. Res., 29, 3699-3708.

Fredlund, D. G., and Rahardjo, H. (1993). Soil mechanics for unsaturated soils, Wiley, New York.

Hakami, E., and Barton, N. (1990). Aperture measurements and flow experiments using transparent replicas. Rock joints, N. Barton and O. Stephansson, eds., Balkema, Rotterdam, 383-390.

Indraratna, B., and Haque, A. (1999). "Triaxial equipment for measuring the permeability and strength of intact and fractured rocks." Geotechnique, 49(4), 515-521.

Indraratna, B., and Ranjith, P. G. (2001). "Laboratory measurement of two-phase flow parameters in rock joints based on high pressure triaxial testing." J. Geotech. Geoenviron. Eng., 127(6), 530-542.

Ishii, M. (1975). Thermo-fluid dynamic theory of two-phase flow, Electricite de France, Paris.

Iwai, K. (1976). "Fundamental studies of fluid flow in a single fracture." $\mathrm{PhD}$ thesis, Univ. of California, Berkeley, Calif.

Keller, A. (1998). "High resolution, nondestructive measurement and characterisation of fracture apertures." Int. J. Rock Mech. Min. Sci., 35(8), 1037-1050.

Keller, A. A., Blunt, M. J., and Roberts, P. V. (2000). "Behavior of nonaqueous phase liquids in fractured porous media under two-phase flow conditions." Transp. Porous Media, 38, 189-203.

Nichol, M. J., and Glass, R. J. (1994). "Wetting phase permeability in a partially saturated horizontal fracture." Proc., 5th Annual Int. High Level Radioactive Waste Management Conf., La Grange Park, Ill., American Nuclear Society, 2007-2019.

Nichol, M. J., and Glass, R. J. (2001). "Simulation of immiscible viscous displacement within the plane of a horizontal fracture." Rock mechanics in the national interest, Elsworth, Tinucci, and Heasley, eds., Swets and Zeitlinger Lisse, 205-210.

Persoff, P., and Pruess, K. (1993). "Flow visualisation and relative permeability measurements in rough walled fractures." Proc., 4th Annual Int. High Level Radioactive Waste Management Conf., Las Vegas, American Nuclear Society, 2033-2041.

Pruess, K., and Tsang, Y. W. (1990). “On two-phase relative permeability and capillary pressure of rough-walled rock fractures." Water Resour. Res., 26, 1915-1926.

Pyrak-Nolte, L. J., Myer, L. A., Cook, N. G., and Witherspoon, P. A. (1987). "Hydraulic and mechanical properties of natural fractures in low permeability rocks." Proc., 6th Int. Congress on Rock Mechanics, ISRM, 225-231.

Rasmussen, T. C. (1991). "Steady fluid flow and travel times in partially saturated fractures using discrete air-water interfaces." Water Resour. Res., 27, 67-76.

Taitel, Y., and Dukler, A. E. (1976). “A model for predicting flow regime transitions in horizontal and near horizontal gas-liquid flow." Am. Inst. Chem. Eng. J., 21, 47-55.

Tsang, Y. W., and Witherspoon, P. A. (1981). "Hydro-mechanical behaviour of deformable rock fracture subject to normal stress." J. Geophys. Res., 86, 9287-9298.

Tsang, Y. W., and Witherspoon, P. A. (1983). "The dependence of fracture mechanical and fluid flow properties on fracture roughness and sample size." J. Geophys. Res., 88, 2359-2366.

Wallis, G. B. (1969). One-dimensional two-phase flow, McGraw-Hill, New York.

Witherspoon, P. A., Wang, J. S. Y., Iwai, K., and Gale, J. E. (1980). "Validity of cubic law for fluid flow in a deformable rock fracture." Water Resour. Res., 16, 1016-1024. 